\title{
Comparative Evaluation of Two Topical Anaesthetic Gels to Reduce Pain During Local Anaesthesia Administration
}

\author{
Hena Mariam Fathima' and Mebin George Mathew ${ }^{2}$ \\ ${ }^{1}$ Saveetha Dental College and Hospitals, Saveetha Institute of Medical and \\ Technical Sciences, Saveetha University, Chennai - 600077, India \\ ${ }^{2}$ Department of Pedodontics and Preventive Dentistry,Saveetha Dental College and Hospitals, Saveetha \\ Institute of Medical and Technical Sciences, Saveetha University, Chennai 600077, India
}

\section{ABSTRACT}

Topical anesthetic agents are widely used in the field of pediatric dentistry to reduce pain and apprehension during administration of local anesthesia. Various topical anesthetic agents are available, among which the most commonly used ones are lignocaine and benzocaine. Hence we planned this study to compare and evaluate the effectiveness of topical anesthesia on needle insertion pain during administration of inferior alveolar nerve block. This double blind clinical study included 50 children of 7-9 years of age who were divided equally into two groups: Group A-2\% lignocaine hydrochloride gel (Lox 2\%) and Group B-20\% benzocaine gel (ProGel-B). The intervention involved assessment of pain perception by the child during administration of inferior alveolar nerve block. The child's pain assessment was done using visual analog scale. The ratings were subjected to statistical analysis. Student paired t- test showed statistically significant difference in the VAS score between Progel B and the LOX in males as well as females. Independent Student t-test showed no statistically significant difference in VAS score between males and females. This study demonstrates that there is a highly significant difference between the topical anesthetic effectiveness of $2 \%$ lignocaine and 20\% benzocaine on needle insertion pain in inferior alveolar nerve block. Twenty percent benzocaine showed better results than $2 \%$ lignocaine in reducing the needle insertion pain.

KEY WORDS: BENZOCAINE; CHILDREN; LIGNOCAINE; PAIN SCALE; PROGEL-B.

\section{INTRODUCTION}

Pain is defined as an unpleasant sensory and emotional experience arising from actual or potential tissue damage or described in terms of such damage.(Zacny et al., 2002) In pediatric dentistry, pain sensation is generated

\section{ARTICLE INFORMATION}

*Corresponding Author: mebingeorgem.sdc@saveetha.com Received 10th June 2020 Accepted after revision 9th August 2020 Print ISSN: 0974-6455 Online ISSN: 2321-4007 CODEN: BBRCBA

Thomson Reuters ISI Web of Science Clarivate Analytics USA and Crossref Indexed Journal

\section{Clarivate}

NAAS Journal Score 2020 (4.31) SJIF: 2020 (7.728)

A Society of Science and Nature Publication,

Bhopal India 2020. All rights reserved.

Online Contents Available at: http//www.bbrc.in/

Doi: http://dx.doi.org/10.21786/bbrc/13.7/58 by stimuli like sound of the drill or touch of the needle at the time of local anesthetic administration and is not necessarily dependent on tissue damage.(Taani and Quteish, 2001) Ointments, anesthetic sprays, gels, or adhesive patch are topical application of local anesthetic which are utilized to reduce pain of local anesthetic injections, but these methods have their own limitations. (Cho et al., 2017)

Anxiety is defined as a state of obnoxiousness with an associated fear of danger from within or a learned process of one's own environment. It mostly depends on the capability to imagine. (Nair and Gurunathan, 2019)Anxiety is the most common issue stumbled upon

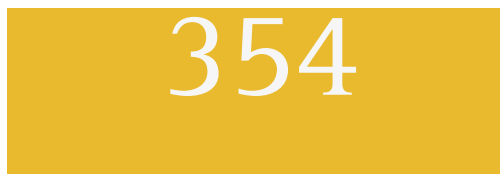


by pedodontists in the dental operatory. Children tend to refuse dental treatment because of which dental anxiety becomes the major source of challenge for pediatric dentists. Dental anxiety is defined as state anxiety as it arises because of the treatment procedure and is associated with negative prospects that are often associated with earlier traumatic experiences, negative outlook of the family, fear of pain and trauma, and perceptions of an unsuccessful previous dental treatment. Few studies claim that there is a significant effect of topical anesthetics on dental anxiety. A randomized clinical trial by Cho et al., stated that highly anxious participants reported higher pain scores, however, topical anesthetic agents reduced the effect of anxiety on needle insertion pain. (Cho et al., 2017)

Injecting local anesthesia in children is in itself an anxiety evoking procedure. (Fiset et al., 1985) In addition, pain management is the vital aspect in pediatric dentistry. The dentist can overcome the issue of injection pain by altering the $\mathrm{pH}$ and temperature of local anesthetic solution and by reducing the speed of injecting the solution into the tissues.(Courtney, Agrawal and Revington, 1999) Another technique is to prepare the tissues before injection, i.e., surface anesthesia, which includes refrigeration, (Ghaderi, Banakar and Rostami, 2013) transcutaneous electronic nerve stimulation (TENS), (Choudhari et al., 2017) and topical anesthesia.

Topical anesthetic gel/ointment is easily available and is not technique sensitive. Hence, topical anesthetic gel/ointment has become the "holy grail" of painless technique of local anesthesia in pediatric dentistry. They have the ability to cross the oral mucosal membrane and produce analgesia. (Ship, Williams and Osheroff, 1960; Adriani et al., 1964) They block the conduction of signals from the terminal fibers of the sensory nerves, thereby producing surface anesthesia for a depth of 2-3 $\mathrm{mm}$. This change takes place secondary to an alteration in transmission through voltage-sensitive sodium channels, resulting in an increment in the action-potential threshold. This trait of topical anesthesia enables it to minimize needle insertion pain effectively.

There are various topical anesthetic agents available ranging from gels to sprays. Benzocaine is most widely used by dentists, and it is rapidly absorbed on the mucosal membrane. It is less soluble in water and is long acting with less toxicity. Topical benzocaine is commercially marketed in 10\% and 20\% concentrations. It is acknowledged as safe and effective as an external source for temporary pain relief owing to minor trauma in mucosa or gingiva, minor dental procedures, teething, etc. Despite its well-documented literature of innocuous use, there have been rare cases of adverse effects such as methemoglobinemia.

Lignocaine is the most commonly used topical anesthetic agent (Vickers and Punnia-Moorthy, 1992) followed by benzocaine. However, there are side effects such as allergic skin reactions, blisters, ulcers, and rarely methemoglobinemia. This research was conducted to evaluate the effectiveness of 2\% lignocaine gel and $20 \%$ benzocaine gel as a topical anesthetic agent prior to administration of local anesthesia. Twenty percent benzocaine gel, i.e., ProGel-B is a new topical anesthetic agent marketed by Septodont Healthcare India Pvt Ltd.

Our department is passionate about child care, we have published numerous high quality articles in this domain over the past 3 years (Govindaraju, Jeevanandan and Subramanian, 2017a, 2017b; Nagaveni et al., 2017; Panchal, Gurunathan and Shanmugaavel, 2017; Ravikumar, Jeevanandan and Subramanian, 2017; Jeevanandan and Govindaraju, 2018; Nair et al., 2018; Ravikumar et al., 2018, 2019; Ravindra et al., 2018, 2019; Subramanyam et al., 2018; Vishnu Prasad et al., 2018; Jeevanandan, Ganesh and Arthilakshmi, 2019; Ramadurai et al., 2019; Ramakrishnan, Dhanalakshmi and Subramanian, 2019; Veerale Panchal, Jeevanandan and Subramanian, 2019; Vignesh et al., 2019; V. Panchal, Jeevanandan and Subramanian, 2019; Mathew, Roopa, et al., 2020; Mathew, Samuel, et al., 2020; Samuel, Acharya and Rao, 2020). With this inspiration we planned to pursue research on comparison and evaluation of two anesthetic gels to reduce pain during local anesthesia administration.

\section{MATERIAL AND METHODS}

The study was a double-blinded randomized controlled clinical trial. This randomized controlled trial compared the effectiveness of two topical anesthetic agents, i.e., $2 \%$ lignocaine gel and 20\% benzocaine gel. For sample size calculation, a sampling error of 5\% was considered, the power was set to $85 \%$ and a minimum sample size of 50 was obtained. The study consisted of 50 healthy children (22 males and 28 females) in the age group of 7-9 years who had bilateral molars that required local anesthesia for dental treatment. Prior to the participation in this study, a medical history was acquired from all the participants, and a brief oral examination was done.

Each child would receive both topical anesthetic agents. To decide which agent each child would get at at the first appointment was decided by coin toss. The other topical agent would be used in the next appointment on the opposite tooth. Group A was 2\% lignocaine gel and Group B was20\% benzocaine gel. The topical anesthetic gel was applied to the test area using a cotton swab applicator that was completely dipped in the gel by the investigator. Following this, $1.2 \mathrm{ml}$ of local anesthetic agent was administered preceded by aspiration through inferior alveolar nerve block onto the areas that were surface anesthetized. The needle was concealed to avoid fear/anxiety-provoking situations in the child as that will alter the pain perception. The child was advised to choose the emoticon that best describes the amount of pain he/she had experienced at the time of needle insertion, and his/her response was recorded by the investigator. The clinical trial for each child was accomplished in a single visit. All the data acquired were analyzed using SPSS software. 


\section{RESULTS AND DISCUSSION}

The total number of participant was 50 and male to female ratio was 22 males (44\%) and 28 females (56\%), their age ranged from $7-10$ years $(8 \pm 1.2)$ years

Table 1. Comparison of LOX gel and ProGel-B based on the gender.

\begin{tabular}{l|c|c|c|c}
\hline Gender & Number & $\begin{array}{c}\text { Mean } \pm \text { SD } \\
\text { VAS (ProgelB) }\end{array}$ & $\begin{array}{c}\text { Mean } \pm \text { SD } \\
\text { VAS (LOX) }\end{array}$ & P Value \\
\hline Male & 22 & $12.5 \pm 8.07$ & $25.3 \pm 11.3$ & 0.000 \\
\hline Female & 28 & $15.1 \pm 10.2$ & $22.2 \pm 10.1$ & 0.011 \\
\hline
\end{tabular}

Student paired t- test showed statistically significant difference in the VAS score between Progel B and the LOX in males as well as females.

Table 2. Comparison of Visual Analogue Scale in male and female in both injection methods

\begin{tabular}{|l|c|c|c|}
\hline $\begin{array}{l}\text { Injection } \\
\text { Method }\end{array}$ & $\begin{array}{c}\text { Mean } \pm \text { SD } \\
\text { VAS in Male }\end{array}$ & $\begin{array}{c}\text { Mean } \pm \text { SD } \\
\text { VAS in Female }\end{array}$ & p Value \\
\hline Progel B & $12.5 \pm 8.07$ & $15.1 \pm 10.2$ & 0.420 \\
\hline LOX & $25.3 \pm 11.3$ & $22.2 \pm 10.1$ & 0.450 \\
\hline
\end{tabular}

Independent Student t-test showed no statistically significant difference in VAS score between males and females Local anesthesia is a combination of two Greek words "an" (without) and "aesthesis" (sensation). In dentistry, local anesthesia is classified on the basis of their effects as (a) Conduction anesthesia, (b) Infiltration anesthesia, and (c) Topical anesthesia. (Boyce, Kirpalani and Mohan, 2016) Local anesthetics are classified into ester linkage agents (benzocaine) and amide linkage agents (lignocaine) and are the most widely used topical anesthetic agents.(Stewart et al., 1982) Topical anesthesia can be defined as loss of sensation on the mucous membrane that is produced by direct application. The first local anesthetic was a topical anesthetic, that is, cocaine and was discovered in 1860 by Albert Niemann. (Wulf et al., 1999)

Benzocaine is a para-aminobenzoic acid ester. Because it has low systemic toxicity, it is safe to use. However, there are rare cases of methemoglobinemia in the literature. Lignocaine is the most widely used local anesthetic agent and is an antiarrhythmic drug. It is eliminated from the body through the liver; hence, its metabolism is compromised in patients with liver dysfunction. Lidocaine acts by blocking the sodium channels, and topical administration of the same blocks ectopic discharges from afferent fibers. Topical application of lidocaine slows down the peripheral nociceptor sensitization and central hyperexcitability. (Jorge, Feres and Teles, 2011)
Topical anesthesia targets the free nerve-endings that reversibly blocks nerve conduction near the site of administration, which in turn induces a temporary loss of sensation in that area. The permeability of cell membrane to sodium ions is decreased, and therefore, nerve conduction is blocked. This eventually decreases the depolarization and increases excitability threshold until the capacity to induce action potential is completely lost.(Kumar, Chawla and Goyal, 2015) Topical anesthesitic agents do not contain vasoconstrictor as it weakens the mucosal permeability. In addition, topical anesthetics are more concentrated than injectable ones to promote diffusion within the mucosa.

In a study conducted by Garg et al., among 30 children (12 males and 18 females) in the age range of 4-8 years to evaluate the efficacy of $2 \%$ lignocaine and $20 \%$ benzocaine as a topical anesthetic agent. Topical anesthesia was used prior to administration of nerve blocks. To standardize the protocol, only mandibular arch and therefore inferior alveolar nerve blocks were included. This study showed a significant difference between the mean pain scores in Group A and Group B. Both the topical anesthetic agents were rubbed with moderate pressure over the surface for $30 \mathrm{~s}$ and left for 1 min. In a clinical trial, 2\% lignocaine gel and 20\% benzocaine gel were compared with placebo, and it was concluded that the effectiveness of both $2 \%$ lignocaine and 20\% benzocaine were similar.(Garg et al., 2016)

Giddon et al. compared topical anesthetic agents in dosage forms and reported that there was no statistical difference among 20\% benzocaine, 5\% lidocaine, and placebo when applied for $30 \mathrm{~s}$ on palate using 25 gauge needle.(Giddon et al., 1968)In a study, benzocaine gel and lignocaine spray were compared, and the results revealed that benzocaine gel had the least VAS score than lignocaine spray,(Koppolu et al., 2016) which corresponds to the findings of the present study. A clinical study of 510 extractions (Grade II and III) were carried out with lignocaine hydrochloride gel 5\% and bupivacaine hydrochloride gel 5\% as topical agents, and it was concluded that 5\% lignocaine hydrochloride gel was better than 5\% bupivacaine hydrochloride gel.(Satya Bhushan and Nayak, 2010).

Another topical anesthetic agent introduced in the 1980s was Eutectic Mixture of Local Anesthetics (EMLA) 5\%. The first clinical study using EMLA was done by Holst and Evers in 1985.(Holst and Evers, 1985) Nayak et al. compared EMLA 5\%, benzocaine 18\%, and lignocaine 5\% in 6-12 years aged children and found out that EMLA 5\% was the best agent in pain reduction than lignocaine and benzocaine. However, taste acceptance was favorable for benzocaine.(Nayak and Sudha, 2006) Di Marco et al. compared the effectiveness of fast acting refrigerant topical agent with 20\% benzocaine in a split mouth study and concluded that both refrigerant and 20\% benzocaine gave similar benefits, however, the refrigerant had a fast onset of action.(DiMarco and Wetmore, 2016) Vongsavan et al. stated that 20\% benzocaine gel was more effective than the placebo in reducing needle insertion pain in 
palatal injections.(Nakrathok et al., 2020)Another clinical trial revealed that 2.5\% lignocaine $+2.5 \%$ prilocaine gave better results than $20 \%$ benzocaine in reducing needle insertion pain in maxillary vestibule.(Al-Melh, Abu Al-Melh and Andersson, 2017).

There are various alternatives to topical anesthesia, but they are much technique sensitive, for example computer-controlled local anesthetic delivery (CCLAD) and TENS. CCLAD works on the idea of slow delivery of local anesthesia. The speed of the delivery of the solution is under computer control. In a clinical trial, comparing CCLAD with conventional method in pediatric patients showed that CCLAD gave better results than the traditional technique.(Mittal et al., 2015) TENS device stimulates the neurons that in turn activates the descending inhibitory system, and hence, hyperalgesia is reduced.

\section{CONCLUSION}

This study demonstrates that there is a high significant difference between the topical anesthetic effectiveness of lignocaine $2 \%$ and benzocaine $20 \%$ on needle insertion pain in inferior alveolar nerve block.

\section{ACKNOWLEDGMENTS}

Nil

Conflict of Interest: None declared.

\section{REFERENCES}

Adriani, J. et al. (1964) 'The comparative potency and effectiveness of topical anesthetics in man', Clinical Pharmacology \&t Therapeutics, 5(1), pp. 49-62.

Al-Melh, M. A., Abu Al-Melh, M. and Andersson, L. (2017) 'The effect of a lidocaine/prilocaine topical anesthetic on pain and discomfort associated with orthodontic elastomeric separator placement', Progress in Orthodontics. doi: 10.1186/s40510-016-0156-7.

Boyce, R. A., Kirpalani, T. and Mohan, N. (2016) 'Updates of Topical and Local Anesthesia Agents', Dental clinics of North America. Elsevier, 60(2), pp. 445-471.

Cho, S.-Y. et al. (2017) 'Effect of Topical Anesthesia on Pain from Needle Insertion and Injection and Its Relationship with Anxiety in Patients Awaiting Apical Surgery: A Randomized Double-blind Clinical Trial', Journal of endodontics, 43(3), pp. 364-369.

Choudhari, S. R. et al. (2017) 'Efficacy of transcutaneous electronic nerve stimulation in alleviating pain during inferior alveolar nerve block injections in pediatric dentistry', International Journal of Pedodontic Rehabilitation. Medknow Publications and Media Pvt. Ltd., 2(2), p. 69.

Courtney, D. J., Agrawal, S. and Revington, P. J. (1999)

'Local anaesthesia: to warm or alter the pH? A survey of current practice', Journal of the Royal College of Surgeons of Edinburgh, 44(3), pp. 167-171.

DiMarco, A. C. and Wetmore, A. 0. (2016) 'Clinical Comparison: Fast-Acting and Traditional Topical Dental Anesthetic', Anesthesia Progress, pp. 55-61. doi: 10.2344/0003-3006-63.2.55.

Fiset, L. et al. (1985) 'Psychophysiological responses to dental injections', The Journal of the American Dental Association. Elsevier, 111(4), pp. 578-583.

Garg, A. et al. (2016) 'Evaluation of efficacy of 2\% lidocaine gel and 20\% benzocaine gel for topical anesthesia', Endodontology. Medknow Publications and Media Pvt. Ltd., 28(1), p. 38.

Ghaderi, F., Banakar, S. and Rostami, S. (2013) 'Effect of pre-cooling injection site on pain perception in pediatric dentistry:“A randomized clinical trial”, Dental research journal. Wolters Kluwer--Medknow Publications, 10(6), p. 790.

Giddon, D. B. et al. (1968) 'Development of a method for comparing topical anesthetics in different application and dosage forms', Journal of oral therapeutics and pharmacology, 4(4), p. 270.

Govindaraju, L., Jeevanandan, G. and Subramanian, E. M. G. (2017a) 'Comparison of quality of obturation and instrumentation time using hand files and two rotary file systems in primary molars: A single-blinded randomized controlled trial', European journal of dentistry, 11(3), pp. 376-379.

Govindaraju, L., Jeevanandan, G. and Subramanian, E. M. G. (2017b) 'Knowledge and practice of rotary instrumentation in primary teeth among indian dentists: A questionnaire survey', Journal of International Oral Health, 9(2), p. 45.

Holst, A. and Evers, H. (1985) 'Experimental studies of new topical anaesthetics on the oral mucosa', Swedish dental journal, 9(5), pp. 185-191.

Jeevanandan, G., Ganesh, S. and Arthilakshmi (2019) 'Kedo file system for root canal preparation in primary teeth', Indian journal of dental research: official publication of Indian Society for Dental Research, 30(4), pp. 622-624.

Jeevanandan, G. and Govindaraju, L. (2018) 'Clinical comparison of Kedo-S paediatric rotary files vs manual instrumentation for root canal preparation in primary molars: a double blinded randomised clinical trial', European archives of paediatric dentistry: official journal of the European Academy of Paediatric Dentistry, 19(4), pp. 273-278.

Jorge, L. L., Feres, C. C. and Teles, V. E. P. (2011) 'Topical preparations for pain relief: efficacy and patient adherence', Journal of pain research. Dove Press, 4, p. 11 .

Koppolu, P. et al. (2016) ‘Comparison of efficacy among 
various topical anesthetics: an approach towards painless injections in periodontal surgery', Saudi journal of anaesthesia. Wolters Kluwer--Medknow Publications, 10(1), p. 55.

Kumar, M., Chawla, R. and Goyal, M. (2015) 'Topical anesthesia', Journal of anaesthesiology, clinical pharmacology. Wolters Kluwer--Medknow Publications, 31(4), p. 450.

Mathew, M. G., Samuel, S. R., et al. (2020) 'Evaluation of adhesion of Streptococcus mutans, plaque accumulation on zirconia and stainless steel crowns, and surrounding gingival inflammation in primary molars: Randomized controlled trial', Clinical oral investigations. Springer, pp. 1-6.

Mathew, M. G., Roopa, K. B., et al. (2020) 'Evaluation of clinical success, parental and child satisfaction of stainless steel crowns and zirconia crowns in primary molars', Journal of Family Medicine and Primary Care. Wolters Kluwer--Medknow Publications, 9(3), p. 1418.

Mittal, M. et al. (2015) 'Pain Perception: Computerized versus Traditional Local Anesthesia in Pediatric Patients', Journal of Clinical Pediatric Dentistry, pp. 470-474. doi: 10.17796/1053-4628-39.5.470.

Nagaveni, N. B. et al. (2017) 'Volumetric evaluation of various obturation techniques in primary teeth using cone beam computed tomography--An in vitro study', Journal of the Indian Society of Pedodontics and Preventive Dentistry. Medknow Publications, 35(3), p. 244.

Nair, M. et al. (2018) 'Comparative evaluation of postoperative pain after pulpectomy with k-files, kedo-s files and mtwo files in deciduous molars -a randomized clinical trial', Brazilian Dental Science, 21(4), p. 411. Nair, M. and Gurunathan, D. (2019) 'Comparative evaluation of the efficacy of two anesthetic gels (2\% lignocaine and 20\% benzocaine) in reducing pain during administration of local anesthesia--A randomized controlled trial', Journal of anaesthesiology, clinical pharmacology. Wolters Kluwer--Medknow Publications, 35(1), p. 65.

Nakrathok, P. et al. (2020) 'The effect of selective carious tissue removal and cavity treatments on the residual intratubular bacteria in coronal dentine', Journal of Dental Sciences. doi: 10.1016/j.jds.2020.03.016.

Nayak, R. and Sudha, P. (2006) 'Evaluation of three topical anaesthetic agents against pain : A clinical study', Indian Journal of Dental Research, p. 155. doi: 10.4103/0970-9290.29871.

Panchal, V., Gurunathan, D. and Shanmugaavel, A. K. (2017) 'Smartphone application as an aid in determination of caries risk and prevention: A pilot study', European journal of dentistry, 11(4), pp. 469-
474.

Panchal, V., Jeevanandan, G. and Subramanian, E. (2019) 'Comparison of instrumentation time and obturation quality between hand K-file, H-files, and rotary Kedo-S in root canal treatment of primary teeth: A randomized controlled trial', Journal of the Indian Society of Pedodontics and Preventive Dentistry, 37(1), pp. 75-79.

Panchal, V., Jeevanandan, G. and Subramanian, E. M. G. (2019) 'Comparison of post-operative pain after root canal instrumentation with hand K-files, H-files and rotary Kedo-S files in primary teeth: a randomised clinical trial', European archives of paediatric dentistry: official journal of the European Academy of Paediatric Dentistry, 20(5), pp. 467-472.

Ramadurai, N. et al. (2019) 'Effectiveness of 2\% Articaine as an anesthetic agent in children: randomized controlled trial', Clinical oral investigations, 23(9), pp. 3543-3550.

Ramakrishnan, M., Dhanalakshmi, R. and Subramanian, E. M. G. (2019) 'Survival rate of different fixed posterior space maintainers used in Paediatric Dentistry - A systematic review', The Saudi dental journal, 31(2), pp. 165-172.

Ravikumar, D. et al. (2018) 'DNA profiling of Streptococcus mutans in children with and without black tooth stains: A polymerase chain reaction analysis', Dental research journal, 15(5), p. 334.

Ravikumar, D. et al. (2019) 'Evaluation of McNamara's analysis in South Indian (Tamil Nadu) children between 8-12 years of age using lateral cephalograms', Journal of oral biology and craniofacial research, 9(2), pp. 193-197.

Ravikumar, D., Jeevanandan, G. and Subramanian, E. M. G. (2017) 'Evaluation of knowledge among general dentists in treatment of traumatic injuries in primary teeth: A cross-sectional questionnaire study', European journal of dentistry, 11(2), pp. 232-237.

Ravindra, V. et al. (2018) 'A comparative evaluation between dermatoglyphic patterns and different terminal planes in primary dentition', Journal of clinical and experimental dentistry, 10(12), pp. e1149-e1154.

Ravindra, V. et al. (2019) 'A comparative evaluation between cheiloscopic patterns and the permanent molar relationships to predict the future malocclusions', Journal of clinical and experimental dentistry, 11(6), pp. e553-e557.

Samuel, S. R., Acharya, S. and Rao, J. C. (2020) 'School Interventions-based Prevention of Early-Childhood Caries among 3-5-year-old children from very low socioeconomic status: Two-year randomized trial', Journal of public health dentistry, 80(1), pp. 51-60.

Satya Bhushan, N. V. V. and Nayak, R. N. (2010) 'A 
comparison of the efficacy of topical application of Lignocaine Hydrochloride 5\% gel and Bupivacaine Hydrochloride 5\% gel for extraction of teeth', Journal of maxillofacial and oral surgery, 9(2), pp. 119-126.

Ship, I. I., Williams, A. F. and Osheroff, B. J. (1960) 'Development and clinical investigation of a new oral surface anesthetic for acute and chronic oral lesions', Oral surgery, oral medicine, and oral pathology, 13(5), pp. 630-636.

Stewart, R. E. et al. (1982) 'Text Book of Pediatric Dentistry: Scientific Foundations and Clinical Practice', St Louis: CV Mosby Co, pp. 87-109.

Subramanyam, D. et al. (2018) 'Comparative evaluation of salivary malondialdehyde levels as a marker of lipid peroxidation in early childhood caries', European journal of dentistry, 12(1), pp. 67-70.

Taani, D. S. M. Q. and Quteish, D. S. (2001) 'Dental fear among a young adult Saudian population', International Dental Journal, pp. 62-66. doi: 10.1002/j.1875595x.2001.tb00823.x.

Vickers, E. R. and Punnia-Moorthy, A. (1992) 'A clinical evaluation of three topical anaesthetic agents',
Australian dental journal, 37(4), pp. 266-270.

Vignesh, R. et al. (2019) 'Management of Complicated Crown-Root Fracture by Extra-Oral Fragment Reattachment and Intentional Reimplantation with 2 Years Review', Contemporary clinical dentistry, 10(2), pp. 397-401.

Vishnu Prasad, S. et al. (2018) 'Report on oral health status and treatment needs of 5-15 years old children with sensory deficits in Chennai, India', Special care in dentistry: official publication of the American Association of Hospital Dentists, the Academy of Dentistry for the Handicapped, and the American Society for Geriatric Dentistry, 38(1), pp. 58-59.

Wulf, H. et al. (1999) 'Ropivacaine Epidural Anesthesia and Analgesia Versus General Anesthesia and Intravenous Patient-Controlled Analgesia with Morphine in the Perioperative Management of Hip Replacement', Anesthesia \& Analgesia, pp. 111-116. doi: 10.1213/00000539-199907000-00019.

Zacny, J. P. et al. (2002) 'Preoperative dental anxiety and mood changes during nitrous oxide inhalation', The Journal of the American Dental Association, 133(1), pp. 82-88. 